Revistade
Economila
Contemporâned

\title{
A EVOLUÇÃO DA MACROECONOMIA MODERNA ENTRE PERSPECTIVAS: EM BUSCA DE UMA SISTEMATIZAÇÃO
}

\author{
Hélio Afonso de Aguilar Filho ${ }^{a}$ \\ Hermógenes Saviani Filho ${ }^{b}$ \\ aProfessor Adjunto da Universidade Federal do Rio Grande do Sul.

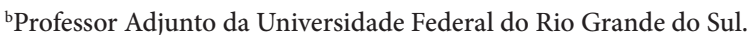

Artigo recebido em 22/02/2017 e aprovado em 11/07/2017.

\begin{abstract}
RESUMO: Longe de ser uma reconstrução sintética de autores e ideias, a história do pensamento econômico se apresenta mais como narrativas entrecortadas por perspectivas distintas. Uma mostra disso pode ser encontrada em Keynes, que construiu sua teoria geral ao se opor ao que no seu entendimento seria a Escola Clássica, mas que abrangia a teoria neoclássica. Apesar das objeções ao solecismo de Keynes, a história das ideias econômicas passou, sem muitas ressalvas, a ser contada incorporando sua definição. Esse artigo busca sistematizar as principais contribuições à Macroeconomia a partir de duas perspectivas analíticas distintas, a de Keynes e a convencional, sumarizada por Joan Robinson. Sustentar-se-á que as diferentes classificações operadas por estas distintas abordagens geram indefinições na análise a respeito dos aspectos coincidentes e contraditórios das diversas teorias macroeconômicas.
\end{abstract}

PALAVRAS-CHAVE: Keynes; Joan Robinson; macroeconomia; história das ideias econômicas; economia clássica; economia neoclássica.

CLASSIFICAÇÃO JEL: B22; B30; E12; E13.

Correspondência para: Hélio Afonso de Aguilar Filho

Contato: haaf73@yahoo.com.br 


\title{
THE EVOLUTION OF MODERN MACROECONOMICS BETWEEN PERSPECTIVES: IN SEARCH OF LOST SINTHESHIS
}

\begin{abstract}
Far from being a synthetic reconstruction of authors and ideas, the history of economic thought is presented more as narratives interspersed with different perspectives. An example of this is Keynes, who built his general theory to oppose the Classical School, but covering the neoclassical theory. Despite objections to the solecism of Keynes, the history of economic thought was reckoned incorporating his definition but few exceptions. The aim of this paper is to analyze the main contributions to macroeconomic thinking from two different analytical cuts, the conventional synthesized by Joan Robinson and that of Keynes. Therefore we argue the use of these different perspectives on understanding of same contents, causes uncertainties in Macroeconomics stopping to adequately consider the overlapping and contradictory aspects of macroeconomic theories.
\end{abstract}

KEYWORDS: Keynes; Joan Robinson; macroeconomics; history of economic thought; neoclassical synthesis. 


\section{INTRODUÇÃO}

A história de uma área do conhecimento em Ciências Sociais é contada de muitas maneiras. Não há um caminho ideal, mas alguns equívocos comuns podem ser evidenciados em sinal de advertência aos praticantes desse ofício. O primeiro equívoco funda-se na perspectiva que traduz a história das ideias como mera retrospectiva, como se o último estágio do saber fosse o verdadeiro e a investigação do passado se prestasse apenas para dar conta dos erros e dos meios para se chegar à etapa atual. O segundo é o tratamento dessas ideias como repositórios sacralizados e intocáveis, no qual se afigura a impossibilidade de superação do próprio passado. Em ambos os casos os conteúdos da história da ciência perdem seu caráter dinâmico, bem como sua abertura em relação às diversas possibilidades.

Contar a história de uma área do conhecimento é também um exercício de síntese, na medida em que exige agrupar autores, demarcando-os a partir de conjuntos chamados escolas de pensamento. Esse recurso permite entender traços recorrentes e depurar o não essencial, pelo menos a princípio, já que a fluidez da história e seus contornos são por vezes paradoxais e, dependendo de novos cortes propostos, alguns elementos antes dispensados podem reaparecer de outra forma. Dos critérios possíveis de classificar escolas de pensamento nas Ciências Econômicas, é importante destacar aqueles cujas consequências se estendem não somente sobre a leitura do passado, mas sobre o modo atual de tratar as diferentes contribuições em campos específicos. Neste sentido, ao contrapor os clássicos, adeptos da Lei de Say, aos teóricos da Demanda Efetiva, Keynes demarcou o campo para o surgimento da própria Macroeconomia moderna. Apesar disso, os conteúdos dessa disciplina têm sido classificados tendo em conta também outros critérios, particularmente o sugerido por Joan Robinson, que separa clássicos de neoclássicos.

Ao invés de buscar uma síntese das perspectivas, pondo fim às controvérsias, o objetivo desse artigo é sistematizar as principais contribuições à história da Macroeconomia à luz das categorizações de Keynes e da convencional. De modo mais específico, procura, a partir de tal sistematização, elucidar contribuições, influências e percursos, permitindo apreciar de forma mais clara o desenrolar da disciplina. Isto se justifica porque as classificações operadas ao mesmo tempo por estas distintas perspectivas geram indefinições na análise a respeito dos aspectos coincidentes e contraditórios das diversas teorias macroeconômicas.

As seções deste artigo estão divididas da seguinte forma. Além desta introdução, consta uma segunda seção tratando do problema de pesquisa e da forma como as diferentes contribuições à Macroeconomia moderna são abordadas. Segue uma terceira seção onde se contrapõe as contribuições das principais correntes macroeconômicas à luz da definição sumariada por Robinson e da de Keynes. E, por fim, a conclusão. 


\section{A MACROECONOMIA E A HISTÓRIA DAS IDEIAS ECONÔMICAS}

Para o senso comum, a importância da ciência se mede pela extensão com que o conhecimento acumulado produz aplicações práticas. No caso das Ciências Sociais, essas possibilidades tecnológicas apresentam terreno menos fértil. Seu conhecimento é medido pela própria comunidade acadêmica, tendo como referência publicações científicas as quais apresentam as divergências e antagonismos fundamentais postos desde os "fundadores".

A Macroeconomia moderna, apesar da autoridade sobre as diretrizes da política econômica, compartilha das mesmas ambiguidades de todo conhecimento social. Esta possui um "pai fundador", Keynes, que com o livro A Teoria Geral do Emprego, do Juro e da Moeda deu início aos estudos macroeconômicos ao conferir unidade em torno de problemas ainda não solucionados pela teoria dominante à época. Da mesma forma que ocorre nos demais ramos das Ciências Sociais, essa também produz intermináveis controvérsias interpretativas em torno da obra fundadora, abrindo diversas possibilidades teóricas.

Uma controvérsia a ser destacada é com relação à própria definição de Keynes a respeito da Escola Clássica. Sua representação estilizada incluía toda a tradição de Ricardo, Mill, Marshall e demais adeptos da Lei da Say. Blaug (1990) argumenta que ao proceder desse modo Keynes teria cometido uma espécie de falácia retrospectiva, dando origem a falsos enigmas históricos. Para Meek (1971), a forma como a Escola Clássica é abordada na Macroeconomia mais obscurece do que esclarece sobre as verdadeiras descontinuidades com relação aos trabalhos de Smith, Ricardo e Marx. A implicação da Teoria Geral teria sido outra, a de ter propiciado uma espécie de retorno do neoclassicismo para o classicismo, já que Keynes, como Smith e Ricardo, “interessou-se acima de tudo pela questão da oscilação da renda global” (MEEK, 1971, p. 239). Uma segunda controvérsia é quanto ao que designar por keynesiano. Certas imprecisões de Keynes deixaram o caminho aberto à conciliação entre contribuições da renovação keynesiana e elementos da tradição (neo)clássica. Isso ocorreu logo após a publicação da Teoria Geral, com a apresentação do Modelo IS/LL por Hicks (1937) (depois IS/LM) e com a "grande síntese" de Samuelson (1955).

A definição de Keynes dos clássicos e o modo inadequado como explicitou os pontos de ruptura em relação à antiga tradição teórica geraram dificuldades não apenas semânticas, mas pontos de vistas distintos para classificar autores e escolas. O problema é que quando conceitos fundamentais são usados em diferentes acepções na economia, gera-se confusão, impedindo de se organizar e dar adequado sentido às disputas teóricas (BEAUD e DOSTALER, 1995; FONSECA, 1981). Na Macroeconomia

1 O que estava por trás desse movimento, segundo Beaud e Dostaler (1995), foi o advento de uma revolução científica paralela, propondo uma mutação radical de alcance só reconhecido mais tarde, a saber, a matematização da economia. 
moderna, a confusão maior ocorre porque as correntes são apresentadas sob mais de uma perspectiva: algumas são keynesianas e neoclássicas, outras clássicas e neoclássicas e há ainda as que são keynesianas e clássicas.

Os livros textos de história do pensamento, análise ou ideias econômicas quando comparados entre si, refletem bem as indefinições supracitadas. Considerá-los é importante porque a atividade científica ordinária depende fundamentalmente da natureza da educação científica. Os manuais cumprem um papel importante nesse caso, por apresentarem unidade histórica e pedagógica, oferecem conceitos e aplicações direcionadas à interpretação de determinado conjunto de fenômenos. Para o presente trabalho foram selecionados, a partir da bibliografia inicial sugerida por Samuels et al (2004) ${ }^{2}$, os livros textos mais citados (edição em inglês) no portal de periódicos CAPES/MEC 3 . A Tabela 1 mostra a ordem dessas citações e o conteúdo macroeconômico abordado. Quanto às escolas consideradas, teve-se em conta o estabelecido por dois importantes livros de história da macroeconomia, Phelps (1990) e Snowdon e Vane (2005) ${ }^{4}$.

\section{Tabela 1 - Livros textos de história do pensamento econômico}

\begin{tabular}{|c|c|c|}
\hline Autores & $\begin{array}{c}\text { Total de citação em } \\
\text { artigos (a) e resenhas (r) }\end{array}$ & $\begin{array}{c}\text { Aborda as seis escolas } \\
\text { propostas }\end{array}$ \\
\hline 01 - Blaug (1990) & (15) $8 \mathrm{a} ; 7 \mathrm{r}$ & (4) $\mathrm{K} ; \mathrm{VK} ; \mathrm{M} ; \mathrm{NC}$ \\
\hline 02 - Landreth e Colander (2001) & (6) $5 \mathrm{a} ; 1 \mathrm{r}$ & (5) $\mathrm{K}$; VK; M; NC; NK \\
\hline 03 - Hunt e Lautzeheiser (2011) & (5) $2 \mathrm{a} ; 3 \mathrm{r}$ & (4) K; VK; M; PK \\
\hline 04 - Rima (2009) & (5) $2 \mathrm{a} ; 3 \mathrm{r}$ & (3) $\mathrm{K} ; \mathrm{VK} ; \mathrm{M}$ \\
\hline 05 - Ekelund e Hébert (2007) & (5) $2 \mathrm{a} ; 3 \mathrm{r}$ & (3) K; VK; PK; M; NC; NK \\
\hline 06 - Screpanti e Zamagni (2005) & (5) $0 \mathrm{a} ; 5 \mathrm{r}$ & (6) K; VK; PK; M; NC; NK \\
\hline 07 - Brue e Grant (2012) & (4) $2 \mathrm{a} ; 2 \mathrm{r}$ & (6) K; VK; PK; M; NK; NC \\
\hline 08 - Backhouse (1985) & (4) $1 \mathrm{a} ; 3 \mathrm{r}$ & (6) K; VK; PK; M; NC; NK \\
\hline 09 - Beaud e Dostaler (1995) & (4) $1 \mathrm{a} ; 3 \mathrm{r}$ & (6) K; VK; PK; M; NC; NK \\
\hline
\end{tabular}

Notas: K=Keynes; VK=Velhos Keynesianos; M=Monetaristas; NC=Novo-Clássicos e NK= Novo-Keynesianos. Fonte: Elaboração própria com base em dados do Portal de Periódicos CAPES/MEC.

2 Para Samuels et al (2004), a importância dos manuais reside no fato deles participarem daquilo que Hobsbawm (2012) chamou de "invenção das tradições". Com base nisso, dedicam dois capítulos do livro para entender o que diversos autores de manuais pensam sobre a história do pensamento econômico. Muitas das bibliografias consultadas por eles não foram usadas porque a reedição atualizada dessas não contempla os desdobramentos mais recentes da macroeconomia contemporânea, como History of Economic Analysis de Joseph Schumpeter (1954), The Worldly Philosophers de Robert Heilbroner (1953) e The Growth of Economic Thought de Henry Spiegel (1971).

3 É uma biblioteca virtual que reúne e disponibiliza a instituições de ensino e pesquisa no Brasil o acesso a 21.500 revistas internacionais, nacionais e estrangeiras.

4 A escolha desses dois livros se baseia no fato de estes ocuparem o polo oposto do espectro ideológico, um monetarista, o outro pós-keynesiano. Ademais, ambos se complementam na extensão, abarcando conteúdos omitidos pelo outro. A teoria dos Ciclos Econômicos Reais não foi contemplada por entender-se que essa faz parte da abordagem mais ampla da Economia Novo Clássica. As macroeconomias estruturalista, kaleckiana e austríaca, ainda que se constituam em análises importantes, também não foram consideradas devido à sua baixa difusão no ensino acadêmico. 
O ponto de partida é o livro de Blaug (1990), destacado na literatura econômica pela abrangência, rigor e profundidade. Para o autor, a Teoria Geral é de fato revolucionária, ainda que as diferenças estabelecidas por Keynes entre as suas ideias e as antigas tenham sido exageradas. Sobre o desenvolvimento da Macroeconomia desde então, Blaug (1990) usa ao mesmo tempo os termos keynesianos e neokeynesianos para falar de pontos comumente aceitos pelos diversos seguidores de Keynes. Ademais, a Curva de Phillips, as expectativas racionais e o monetarismo são apresentados como desenvolvimentos posteriores e opostos à Revolução Keynesiana. Para Ekelund e Hébert (2007), o surgimento da Macroeconomia ocorre como ruptura de Keynes em relação à Teoria Clássica, essa última identificada pela defesa da Lei de Say e pela flexibilidade de preços e salários. Tal interpretação culmina com a apresentação das Escolas Monetarista e Novo-Clássica, consideradas um retorno à tradição clássica, exatamente por seus praticantes preconizarem a economia laissez-faire. Brue e Grant (2012), em outro manual bem difundido apresentam a interpretação convencional dada pela tradição de Hicks e Samuelson como sendo a própria economia de Keynes. Os progressos ulteriores dessa escola são discutidos em capítulo à parte, e incluem as contribuições dos (novos) neokeynesianos e pós-keynesianos. Os monetaristas e novo-clássicos são apresentados junto à Escola de Chicago em outro capítulo. No fim, o autor liga toda essa tradição à Escola Neoclássica, à exceção é claro dos pós-keynesianos.

Para Landreth e Colander (2001), o ponto crucial para o surgimento da economia keynesiana foi o rompimento de Keynes com a teoria clássica (embora contivesse elementos neoclássicos), que passou a ocupar o lugar de caso especial em seu arcabouço teórico mais geral. Fariam parte da economia keynesiana, tanto os trabalhos desenvolvidos pelos velhos keynesianos (multiplicador da renda, IS/LM e Demanda e Oferta Agregadas), quanto os dos monetaristas. A economia praticada pelos novo-clássicos e pelos novo-keynesianos, apesar do epíteto de keynesianos desses últimos, seria parte do que Landreth e Colander (2001) chamam de Nova Economia. O maior apelo por microfundamentação, difícil de ser concretizada dentro do marco teórico do equilíbrio geral walrasiano, distanciou esses trabalhos do neoclassicismo rumo ao ecletismo ${ }^{5}$. É interessante contrapor a visão desses autores à de Backhouse (1985). Ao dar ênfase à importância das teorias no desenvolvimento da macroeconomia - em detrimento da fundamentação empírica - o autor passa a compreender a evolução desta como um programa de pesquisa progressivo, no sentido empregado por Lakatos (1970). Desse modo, conforme escritos metodológicos posteriores, Backhouse (1996) salienta que

\footnotetext{
5 Essas conclusões fazem parte de uma análise mais ampla de Colander (2000, 2004). Nesses escritos o autor postula a substituição da economia neoclássica como corrente dominante por uma teoria mais complexa, na qual predomina um comportamento de maior abertura dos pesquisadores, interessados em incorporar contribuições de diversas áreas e correntes, inclusive da heterodoxia.
} 
keynesianos, monetaristas, adeptos das expectativas racionais e novo-clássicos trabalhariam todos em torno do core walrasiano do equilíbrio geral, cada qual adaptando seus insights em face de anomalias empíricas e de mudanças no ambiente econômico.

Rima (2008) também vê a Revolução Keynesiana como uma ruptura, tanto com a tradição neoclássica - preocupada com problemas de alocação de recursos - quanto com a ortodoxia clássica e sua noção autocorretiva da economia agregada. Na mesma linha de Leijonhufvud $(1968)^{6}$, a autora estabelece diferenças entre a economia dos keynesianos e a economia de Keynes. A cruz keynesiana e o modelo IS/LM, pilares da macroeconomia contemporânea, são considerados produtos da contrarrevolução promovida por neo-walrasianos e monetaristas. A implicação maior desse movimento, preocupado em demonstrar o equilíbrio geral entre os mercados de commodities, dinheiro e trabalho, seria, segundo Rima (2008), a de ter promovido um retorno à tradição neoclássica rejeitada por Keynes. Outra visão, bem peculiar sobre os conteúdos da Macroeconomia moderna é a de Hunt e Lautzenheiser (2011). Os autores consideram as contribuições a essa disciplina como parte da tradição neoclássica, incluindo as do próprio Keynes como se verá adiante. Dividem, por conseguinte, a Macroeconomia entre duas escolas ligadas ao neoclassicismo, a dos neoclássicos liberais e a dos conservadores. Os que aceitam a participação do governo na economia para corrigir certas falhas são conhecidos por liberais; enquanto os defensores da economia laissez-faire são os conservadores. Na abordagem de Screpanti e Zamagni (2005), a tradição equilibrista denominada neoclássica é contraposta a não equilibrista dos pós-keynesianos. A primeira compreende, de um lado, as perspectivas dos velhos keynesianos e dos novo-keynesianos e, de outro, a dos monetaristas e neomonetaristas ${ }^{7}$.

Por fim, Beaud e Dostaler (1995) procuram dividir as contribuições macroeconômicas de acordo com linhas mais amplas, opõem assim heterodoxos versus ortodoxos. As escolas ligadas a essa última tradição partem de alguns elementos legados pela economia clássica, integrando-os à perspectiva marginalista, com a adesão às noções de homo economicus, racionalidade e defesa do equilíbrio geral. Os autores advertem que a economia neoclássica pode coexistir com várias ideologias e orientações políticas. No entanto, desde o final da década de 1950, a renovação e a generalização da abordagem neoclássica têm andado de mãos dadas com o ressurgimento do liberalismo.

6 Em 1968, Leijonhufvud publicou um influente livro intitulado On Keynesian Economics and the Economics of Keynes. Nele, o autor sustenta que o modelo IS/LM formulado por Hicks (1937) era uma representação inadequada da Teoria Geral de Keynes, já que esse modelo privilegia fundamentalmente as situações de equilíbrio.

7 Togati (1998) contrapõe as correntes equilibristas às não equilibristas. Em analogia com a física estabelece que, enquanto a tradição neoclássica seria mecanicista e equilibrista, a de Keynes da Teoria Geral seria einsteiniana. $\mathrm{O}$ foco antiatomista desta última acabaria conduzindo à rejeição das pretensões de universalidade e de ampla aplicação das teorias e no reconhecimento do papel limitado dos modelos. 
Outro critério que baliza essas distinções de heterodoxo e ortodoxo parece ser que enquanto os primeiros fazem a defesa da instabilidade do sistema capitalista, chamando a atenção para toda forma de imperfeição de uma economia de livre mercado, os segundos sustentam o liberalismo econômico apregoando as vantagens autorreguladoras do mercado. Nem todos, contudo, estão de acordo com esse critério. Cita-se, no caso, Snowdon e Vane (2005, p.102), que apesar de tratarem os velhos keynesianos como "escola ortodoxa keynesiana" aludem o fato de estes conceberem a economia capitalista como sendo “... inerentemente instável e sujeita a choques erráticos".

A falta de consenso sobre as classificações, descrita acima, não é algo necessariamente negativo, reflete menos a falta de unidade teórica na disciplina e mais algo bem típico das Ciências Sociais, a diversidade de perspectivas e as amplas possibilidades de se abordar as distintas contribuições. As próximas duas subseções tratam da Escola Clássica de Economia segundo os pontos de vista convencional e de Keynes.

\subsection{A ESCOLA CLÁSSICA SEGUNDO A VISÃO CONVENCIONAL}

A definição de Robinson e Eatwell (1978) sobre o que significa economia clássica sintetiza a perspectiva mais frequentemente usada para tratar dessa Escola. Para a autora, clássicos são aqueles que estudam as leis da distribuição do produto social pressupondo a existência de classes sociais. Esse produto se divide em duas partes: uma apropriada por aqueles que, por seu trabalho, o produziram; outra, o excedente econômico, apropriada pelos não diretamente envolvidos na produção.

O excedente econômico é uma categoria definida historicamente, no sentido de ser expressão do tipo de sociedade no qual é produzido. Assim, para explicar a sua forma em sociedades cuja produção se realiza, por exemplo, em mercados, os clássicos perceberam ser necessário ter em conta uma teoria que explique porque o valor da produção difere do valor de troca. Nesse sentido, apresentaram a teoria do Valor trabalho, na qual o valor do produto seria determinado pelos custos de produção, medidos em termos de tempo de trabalho.

À economia clássica, Robinson e Eatwell (1978) contrapõe a economia neoclássica desde as contribuições marginalistas. O pensamento marginalista teria surgido aproveitando o novo clima político e ideológico dos fins do século XIX, bem como o fracasso dos clássicos em explicar uma série de problemas puramente teóricos. Com os marginalistas inaugura-se uma nova abordagem para o valor, com a ênfase passando dos custos de produção para as condições de demanda e, portanto, sobre a troca e satisfação individual de necessidades. De acordo com o próprio Menger (1983, p. 305), o decisivo para se determinar o valor, "é a importância maior ou menor da(s) necessidade(s) 
para cujo atendimento temos consciência de depender de um bem"8. Para a produção passou-se a falar não mais em classes sociais, mas em fatores de produção, com a implicação de que cada fator é remunerado por sua produtividade na margem.

Doravante, foram de Marshall (1842-1924) e Walras (1834-1910) os maiores esforços para deslocar a economia clássica e consolidar as contribuições ainda fragmentadas do que seria a teoria neoclássica. Em seus Princípios de Economia, Marshall foi um "sintetizador..., combinando a utilidade marginal com a teoria do valor dos custos de produção" (ROBBINS, 1998, p. 323). Dessa síntese surgiu a análise do equilíbrio de oferta e procura num estado estacionário. Ademais, resultou dela também a descaracterização do pensamento e da teoria do valor trabalho e da distribuição de Ricardo, ocupando seu lugar:

...uma teoria da alocação de recursos escassos a usos específicos, sob o duplo incentivo da maximização da utilidade, para o consumidor e da maximização dos lucros, para o produtor, empregando conceitos, critérios e técnicas de análise que podiam ser aplicados, de forma análoga, a todo o sistema econômico. (DEANE, 1980, p. 145)

Além das contribuições diretas, Marshall deixou sugestões ou indicações sutis de progresso ulterior. Como atesta Schumpeter (1970, p. 107), “[a] literatura econômica nos trinta anos decorridos desde 1890, abunda com o desenvolvimento, as reformulações e os corolários de proposições e aspectos da técnica marshalliana”. Um exemplo disso é a extensão da análise econômica a outras situações que não a de concorrência perfeita, como as de monopólio e concorrência monopolista.

Outro cuja obra foi fundamental para a edificação do pensamento neoclássico é Walras (1874 [2010]). Na sua teoria econômica o autor concebe uma economia completa baseada em mercados e agentes individuais. O ponto central desse arranjo é a concepção segunda a qual, em condições de concorrência perfeita, com métodos de produção conhecidos e com agentes racionais manifestando suas preferências através dos sinais dos preços (escassez), é possível determinar o equilíbrio simultâneo de preços e quantidades transacionadas em todos os mercados (ROBINSON e EATWELL, 1978). Embora as ideias de Marshall tenham sido o principal veículo do ensino universitário da economia neoclássica até a grande depressão, os conceitos herdados de Wal-

\footnotetext{
8 Ainda segundo Menger (1983, p. 305) "nem a quantidade de trabalho ou de outros bens necessários para a produção, ou para a reprodução de um bem, constitui o fator decisivo para se determinar o valor dos mesmos". Jevons (1983, p. 28), outro expoente do marginalismo também assinala que basta seguir "as leis naturais da variação da utilidade, enquanto dependendo da quantidade de mercadoria em nosso poder, para que cheguemos a uma teoria de troca satisfatória, das quais as leis comuns de oferta e demanda são uma consequência necessária”.
} 
ras foram os principais responsáveis pelo renascimento desta escola no Pós-Segunda Guerra. Isto aconteceu na medida em que houve esforços no sentido de enquadrar as contribuições de Keynes e dos neoclássicos partindo de um modelo de equilíbrio geral.

Mas existe uma definição capaz de dar sentindo e unidade às contribuições da "primeira síntese neoclássica”? Segundo Robinson e Eatwell (1978), a economia neoclássica pode ser definida como o estudo das trocas de bens e serviços sob a diferença de preços relativos, formados com base nas preferências subjetivas de produtores e consumidores.

Quadro 1 - Clássicos e marginalistas na perspectiva convencional

\begin{tabular}{|c|c|}
\hline $\begin{array}{c}\text { Valor do produto } \\
\text { determinado pela }\end{array}$ & $\begin{array}{c}\text { Visão convencional: } \\
\text { perspectiva micro }\end{array}$ \\
\hline Oferta & Clássicos \\
\hline Demanda & Marginalistas \\
\hline Oferta e demanda & Primeira Síntese Neoclássica \\
\hline
\end{tabular}

Fonte: Elaborado pelos autores a partir de Robinson e Eatwell (1978) e Fonseca (1981).

O Quadro 1 é uma súmula da discussão desenvolvida até então. Nele, clássicos e marginalistas são classificados pela tentativa de determinação do valor na perspectiva micro. Enquanto os primeiros enfatizam o trabalho e os custos de produção, os marginalistas sustentam a demanda como força principal na determinação do valor, inclusive dos bens de capital. Já os neoclássicos, atingem maior nível de generalidade na explicação da determinação do valor ${ }^{9}$. Conforme ilustrado pelas famosas tesouras marshallianas ${ }^{10}$, consideram não apenas os aspectos subjetivos do lado da demanda ou os custos de produção do lado da oferta, mas a interação entre a demanda e a oferta.

\subsection{A ESCOLA CLÁSSICA SEGUNDO KEYNES}

Diferentemente de Robinson, Keynes não contrapõe a Escola Clássica aos marginalistas e neoclássicos, mas aos teóricos da Demanda Efetiva. A sua definição da economia clássica inclui autores que na perspectiva convencional seriam neoclássicos. Segundo palavras do próprio Keynes (1985, p. 15) “acostumei-me, talvez perpetrando um sole-

9 Marshall inverte a relação ao passar a medir as preferências de acordo com a escala financeira de pagamentos; pagar duas vezes por um bem em relação a outro implica que esse bem possui duas vezes a utilidade do outro.

${ }^{10}$ Em passagem exaustivamente reproduzida de sua obra, Marshall (1920, p. 348) afirma: "[o] custo de produção e o grau final de utilidade, sem dúvida, são partes que compõem a oferta e a procura; cada um pode ser comparado com um par de lâminas de uma tesoura. Quando um lado da tesoura está parado e o corte é feito movendo o outro, podemos afirmar com cautela que o corte é feito pelo segundo. Mas a declaração não pode ser sustentada cientificamente, nem defendida deliberadamente". 
cismo, ao incluir na 'escola clássica' os seguidores de Ricardo, ou seja, os que adotaram e aperfeiçoaram sua teoria, compreendendo (por exemplo) J. S. Mill e o Prof. Pigou”.

Clássicos para Keynes são aqueles autores adeptos da Lei de Say. Esse postulado, defendido pelo economista francês Jean-Baptiste Say e difundido por John Stuart Mill, sugere que toda a oferta gera sua própria demanda, sendo impossíveis crises de superprodução. A ocorrência de desemprego de fatores só é concebível pela recusa dos trabalhadores em aceitarem emprego ao nível do salário que remunera sua produtividade na margem, o chamado desemprego voluntário. Em geral, os seguidores de Say confiam plenamente nos mecanismos concorrenciais para alcançar situações ótimas, defendendo os princípios do laissez-faire. Em resumo, o principal aspecto que une os clássicos na perspectiva keynesiana é o da impossibilidade de crises de Demanda Efetiva no sistema capitalista.

Keynes apresenta em oposição aos clássicos os teóricos da Demanda Efetiva. Estes, de acordo com Fonseca (1981, p. 51-52), procuraram mostrar que:

...no sistema econômico que teve lugar após a Revolução Industrial, há permanente defasagem entre a acumulação de capital, que se dá em altas taxas, e a capacidade de formar Demanda Efetiva suficiente para que todos os recursos, homens e máquinas sejam plenamente empregados.

Na Teoria Geral, são apresentados diversos aspectos fundamentais à compreensão das economias capitalistas. Os principais incluem a análise dos investimentos como determinantes da renda e da poupança, as contribuições à teoria monetária, ligando o lado monetário da economia com o lado real, a ideia de que a renda cresce proporcionalmente mais que o consumo, gerando crises de demanda e instabilidade econômica. Os precursores das ideias de Keynes foram Sismondi, Malthus e Hobson, todos ressaltando as deficiências da Demanda Efetiva como causa das crises capitalistas. Antecedendo ainda tais autores, os fundamentos das ideias keynesianas podem ser encontrados na doutrina mercantilista. A concepção dos autores mercantilistas sobre a necessidade de se manter uma balança comercial favorável mostra como o excesso de exportações sobre as importações permite pressionar para baixo a taxa de juros, incentivando os investimentos e a manutenção do nível de renda internamente.

Quadro 2 - Clássicos e teóricos da demanda efetiva na perspectiva de Keynes

\begin{tabular}{|c|c|}
\hline $\begin{array}{c}\text { Valor do produto } \\
\text { determinado pela }\end{array}$ & $\begin{array}{c}\text { J. M. Keynes: } \\
\text { perspectiva macro }\end{array}$ \\
\hline Oferta & Clássicos \\
\hline Demanda & Teóricos da Demanda (Efetiva) \\
\hline Oferta e demanda & Segunda Síntese Neoclássica \\
\hline
\end{tabular}

Fonte: Elaborado pelos autores a partir de Robinson e Eatwell (1978) e Fonseca (1981). 
O Quadro 2 resume a preocupação fundamental de Keynes, diferenciar os clássicos, partidários da noção de tendência ao pleno emprego, dos teóricos da instabilidade, ou defensores da Demanda Efetiva. Enquanto para os primeiros, o nível de produto agregado seria determinado pela oferta, para os últimos seria a demanda a variável principal. A “segunda síntese neoclássica”, como será visto, busca integrar os principais blocos de construção da Teoria Geral com os postulados de comportamento racional e maximização dos agentes econômicos. Para os autores da "Síntese", o pleno emprego deixa de ocorrer sob o laissez-faire, passando a depender, no curto prazo ${ }^{11}$, do uso adequado da política monetária e fiscal. No longo prazo, restabelece-se a primazia da oferta. Portanto, tanto a Demanda Keynesiana quanto a Oferta Agregada dos clássicos passam, cada qual em certo período de tempo, a ter importância na determinação do nível de renda.

\section{A EVOLUÇÃO DA MACROECONOMIA MODERNA ENTRE SÍNTESES}

Na última seção considerou-se a existência de imprecisões que dificultam o entendimento a respeito dos conteúdos da Macroeconomia moderna. Essas imprecisões foram destacadas à luz dos livros textos de história do pensamento econômico. Nesses, constatou-se que a relação entre as correntes macroeconômicas e as abordagens originais dos clássicos, neoclássicos e de Keynes é feita de modo pouco satisfatório. Em decorrência, algumas questões persistem, como por exemplo: existe algo ligando a macroeconomia clássica praticada recentemente à antiga tradição de Smith, Malthus e Marx? Existe uma macroeconomia neoclássica? Quem são os keynesianos de fato, a vertente equilibrista ou os que se apoiam na noção de instabilidade capitalista? Não se deve omitir também que algumas dessas correntes recebem dupla denominação, o caso mais comum é o dos keynesianos neoclássicos. Isso levanta questão adicional: é possível uma corrente ser ao mesmo tempo neoclássica e keynesiana, ou clássica e neoclássica, ou ainda, clássica e keynesiana?

${ }^{11}$ Marshall concebeu a existência de distintos tempos da produção, a saber, o presente imediato, o curto prazo e o longo prazo. O que distingue o longo prazo é que o custo de produção assumiria uma proeminência maior na determinação do valor, dado que durante esse período seria possível ajustar completamente a estrutura produtiva das empresas. A "síntese neoclássica” da década de 1950 aplica esses conceitos para entender a determinação do produto em nível agregado. Assim, haveria espaço para políticas de promoção da demanda apenas no curto prazo, já que no longo prazo o produto seria determinado pela oferta. 
Os problemas suscitados até então derivam de se tratar de casos onde se usa paralelamente critérios distintos de classificação para se referir às diversas contribuições. Num caso, está se aplicando o ponto de vista convencional, no qual, clássicos e neoclássicos são contrapostos na perspectiva micro; enquanto noutro, os clássicos são contrapostos aos keynesianos (defensores da Demanda Efetiva) na perspectiva macro. A distinção entre as disciplinas Microeconomia e Macroeconomia das perspectivas micro e macro de classificação é a princípio meramente formal, já que ambos os pares de conceitos coincidem ${ }^{12}$. A Microeconomia enquanto disciplina científica foi fundada pela Escola Neoclássica, tendo como ponto de partida o foco no modo como as unidades individuais que compõe a economia interagem umas com as outras. Para contrastar, basta lembrar que as funções de agregação dos economistas clássicos não se baseavam em premissas microeconômicas putativas, mas em conjecturas plausíveis ou hipóteses sobre o comportamento do sistema como um todo (MILONAKIS e FINE, 2009). Já as ideias de Keynes consolidaram a separação macro e micro porque o foco do autor teria recaído inteiramente na determinação do rendimento em termos agregados.

O Quadro 3 apresenta a discussão sobre as Escolas começando com a Revolução Keynesiana, episódio que funda os estudos nessa área com base na noção macro de Demanda Efetiva contraposta à visão consagrada da Lei de Say. Sob o ponto de vista micro, apesar de aceitar os diversos postulados neoclássicos, Keynes desconsidera a influência desses sobre a determinação do produto em termos agregados. Em seguida apresenta a "segunda síntese neoclássica", cuja abordagem incorpora os pressupostos keynesianos ao modelo agregado clássico, fundindo-os ao mesmo tempo à Microeconomia neoclássica (essa última, uma junção feita por Marshall das abordagens Clássicas e Marginalistas). Mostra também as correntes Monetarista, Novo-Clássica e Novo-Keynesiana. Enquanto as duas primeiras têm abordagens macro semelhantes à corrente Clássica, os novo-keynesianos aceitam alguns dos pressupostos keynesianos sobre a determinação do produto no agregado. Finalmente, são apresentadas duas correntes heterodoxas. A dos Pós-Keynesianos Fundamentalistas e a dos Pós-Keynesianos Neo-Ricardianos. Os primeiros são adeptos das ideias originais de Keynes e críticos a qualquer tentativa de descaracterizá-las através da junção com as noções neoclássicas; os segundos são favoráveis à teoria do valor dos clássicos, ao incorporarem as contribuições de Piero Sraffa.

12 Apesar dos neoclássicos terem se preocupado em alguma medida com análises agregativas, como demanda total, oferta total de moeda, poupança total e investimento total, isso não é suficiente para atestar a formação de uma disciplina específica como a Macroeconomia por parte dessa corrente. 
Quadro 3 - A evolução da macroeconomia entre perspectivas

\begin{tabular}{|l|c|c|}
\hline \multicolumn{1}{|c|}{$\begin{array}{c}\text { Correntes } \\
\text { macroeconômicas }\end{array}$} & $\begin{array}{c}\text { Perspectiva } \\
\text { micro }\end{array}$ & $\begin{array}{c}\text { Perspectiva } \\
\text { macro }\end{array}$ \\
\hline Revolução Keynesiana & $\begin{array}{c}\text { Sem Perspectiva Micro; } \\
\text { Ou Neoclássica }\end{array}$ & Demanda (Efetiva) \\
\hline $\begin{array}{l}\text { Segunda Síntese Neoclássica } \\
\text { (Velhos Keynesianos) }\end{array}$ & Neoclássica & Demanda (Agregada) \\
\hline Monetaristas & Neoclássica & Clássica \\
\hline Novo-Clássicos & Neoclássica & Clássica \\
\hline Novo-Keynesianos & Neoclássica & Demanda (Agregada) \\
\hline $\begin{array}{l}\text { Pós-Keynesianos (Fundamentalistas e } \\
\text { Neo-Ricardianos) }\end{array}$ & $\begin{array}{c}\text { Sem Perspectiva Micro; } \\
\text { Ou Clássica }\end{array}$ & Demanda (Efetiva) \\
\hline
\end{tabular}

Fonte: Elaborado pelos autores.

O objetivo principal das subseções a seguir não é o de buscar uma síntese ou a conciliação entre os distintos planos micro e macro de classificação, mas sistematizar as contribuições e a disposição de cada corrente macroeconômica segundo a perspectiva contida em cada um desses planos de análise.

\subsection{A REVOLUÇÃO KEYNESIANA}

As ideias de Keynes na Teoria Geral promoveram o nascimento de uma nova economia. De acordo com Deane $(1980)^{13}$, três aspectos contribuíram nesse sentido. Primeiro, a maneira como o autor formulou o problema teórico fundamental, ao invés de explicar o nível de preços, buscou explicar o nível de atividade econômica; segundo, com o método, ao apresentar o quadro analítico referencial de renda-despesa nacional e; por fim, pelas implicações práticas em termos da administração da demanda por parte das autoridades políticas e monetárias.

A análise de Keynes apoia-se, como o título do livro indica, em uma teoria geral cujo objetivo é explicar não somente as situações pouco comuns de equilíbrio com pleno emprego dos clássicos, mas as diversas situações de equilíbrio com desemprego. De acordo com a caracterização convencional, as contribuições à análise econômica podem ser clássicas ou neoclássicas. Partindo desta perspectiva, não há nada que permita afirmar que Keynes seja um clássico; quanto a ser neoclássico, vale lembrar que o escopo fundamental dessa corrente é buscar explicações que relacionem a determi-

${ }_{13}$ Primeiro, chamou a atenção para o fato de a teoria econômica dominante à época não conseguir dar explicações para os determinantes da oferta e demanda do produto agregado. Segundo, demonstrou não haver uma mão invisível que traduzisse o interesse individual privado em benefício social. E, terceiro, apresentou um modelo agregativo da economia como um todo, o que culminou com o nascimento de uma disciplina específica, a Macroeconomia do Pós-Segunda Guerra. 
nação de preços à tomada ótima de decisões por parte dos indivíduos e das empresas. Nesse sentido, o próprio Keynes não cansou de reconhecer em muitas passagens sua relação para com o pensamento herdado, sendo que a contribuição da Teoria Geral teria sido "menos em revelar os defeitos lógicos de sua análise [neoclássica] do que em assinalar o fato de que as suas hipóteses tácitas nunca ou quase nunca são satisfeitas" (KEYNES, 1996, p. 345). Na mesma página reconhece também que se pressuposto o nível de produto, não tinha nada a opor "à maneira como o interesse pessoal determinará o que se produz especificamente, em que proporção se associarão os fatores para tal fim e como se distribuirá entre eles o valor da produção obtida”.

A questão de saber se Keynes está de acordo com os princípios neoclássicos bem como a importância e extensão destes dentro da sua argumentação permanece em aberto, no sentido de sujeito a controvérsias. Para Rima (2008), a própria capacidade de influência exercida por Keynes sobre seus contemporâneos neoclássicos seria mostra de seu treinamento neoclassicista estrito. Segundo Hunt e Lautzenheiser (2011), por exemplo, Keynes reafirma constantemente os principais postulados da teoria neoclássica, sendo o principal o da remuneração dos fatores de produção pelas respectivas contribuições marginais dos agentes. Isto pode ser depreendido da análise do mercado de trabalho na Teoria Geral, no qual aceita o postulado de que os salários se igualam ao produto do trabalho na margem. Ainda de acordo com Hunt e Lautzenheiser (2011), mesmo quando Keynes rompe com o neoclassicismo é com ressalvas, como acontece em relação ao segundo postulado e a afirmação de que os trabalhadores estão em condições de fixar o volume de trabalho a ser ofertado de acordo com o salário real pretendido.

A controvérsia sobre o segundo postulado se estende também entre os próprios seguidores das ideias de Keynes. Para os keynesianos mais heterodoxos, a discussão sobre o mercado de trabalho tem apenas caráter expositivo e retórico dado que a verdadeira ruptura estaria em negar o pressuposto microeconômico de que as firmas tomadas individualmente tenham condições de fixar o nível geral de emprego. Portanto, muito mais do que um problema de rigidez em mercados específicos, o emprego total seria determinado pelos gastos agregados, ou seja, a Demanda Efetiva ${ }^{14}$. Meek (1971, p. 239) acrescenta, “... o que ele [Keynes] combatia, no fundo, era a contínua preocupação da maioria dos economistas com a análise microeconômica numa época em que os problemas práticos em pauta exigiam a análise macroeconômica”.

${ }^{14}$ As decisões de gasto determinam o nível de emprego porque, em relação ao mercado de trabalho, ainda que cortes nos salários das empresas sejam uma boa política para as firmas tomadas individualmente, em termos agregados podem levar à redução da Demanda e queda nos preços, neutralizando os cortes de salários. 
Para os keynesianos da "síntese neoclássica", tratados a seguir, a rigidez no mercado de trabalho, ao lado da rigidez da taxa de juros (preferência pela liquidez por reter moeda), são os principais elementos na explicação do desemprego, pois se constituem em falha de mercado.

\subsection{A SEGUNDA SÍNTESE NEOCLÁSSICA: OS VELHOS KEYNESIANOS}

Nas décadas de 1940 e 1950 havia um consenso macroeconômico englobando a produção de importantes economistas como Hicks, Modigliani, Solow e Tobin (aqui chamados velhos keynesianos). Esse consenso foi obtido ao se compatibilizar o núcleo válido das ideias keynesianas sobre a determinação do rendimento agregado com os princípios microeconômicos neoclássicos (DE VROEY e DUARTE, 2013). O termo "síntese neoclássica", cunhado inicialmente por Samuelson em 1955, na $3^{a}$ edição do seu livro Economics, aparece precisamente para descrever as formas pelas quais seria possível vincular ambas as tradições. No prefácio do seu livro o autor adverte: "Repetidamente no livro tenho estabelecido o que chamo uma 'grande síntese neoclássica'. Esta é uma síntese do (1) núcleo válido de determinação do rendimento moderno, com (2) os princípios econômicos clássicos" (SAMUELSON, 1955, p. VI).

Essa "síntese" significou também a tentativa de unir a macroeconomia dos clássicos à de Keynes. Do lado dos clássicos continua valendo a dicotomia entre o lado real e monetário, só que no longo prazo, com o produto de pleno emprego determinado pelo acúmulo de capital, trabalho e tecnologia. Do lado keynesiano, as políticas econômicas de fomento à renda tem validade quando praticadas no curto prazo, período onde há rigidez de preços e salários. Já a ambicionada clivagem entre a Microeconomia neoclássica e a Macroeconomia keynesiana tornou-se possível graças à associação dessa última ao equilíbrio geral walrasiano. A noção é que um sistema interdependente de mercados tende para um equilíbrio geral porque, mesmo quando um ou mais mercados estiver em desequilíbrio, haverá ajustamento de preços que levará oferta e demanda a se igualarem em todos os mercados. Assim, o domínio no longo prazo passou a ser das teorias clássicas (definição de Keynes) e neoclássicas (definição de Robinson), por apresentar os atributos de flexibilidade de preços e salários e equilíbrio do mercado.

O próprio modelo IS/LM ${ }^{15}$ foi concebido para sintetizar os resultados econômicos keynesianos de curto prazo com o arcabouço walrasiano. Nele, Hicks (1937) e Hansen

\footnotetext{
15 A curva IS mostra a relação de equilíbrio no mercado de bens; enquanto a curva LM mostra o equilíbrio no mercado monetário. A interação entre ambas e a renda é feita por intermédio da taxa de juros.
} 
(1936) apresentam o nível de renda em termos de equilíbrio de mercado de bens e serviços e no mercado monetário. As decisões de política econômica, tanto monetárias quanto fiscais, são medidas exógenas determinadas pela autoridade do governo. Outra incorporação à caixa de ferramentas dos velhos keynesianos foi a Curva de Phillips ${ }^{16}$ nos fins da década de 1950 com a constatação da relação negativa entre inflação e desemprego (KLAMER, 1983). Desta forma, o comportamento dos preços considerados constantes no curto prazo, passou a ser analisado como uma relação estável com o desemprego. $\mathrm{O}$ resultado foi a possibilidade de conceber a prática de políticas econômicas a partir da escolha da combinação desejada de desemprego e inflação.

A consequência da "segunda síntese neoclássica" é que as suas formulações acabaram negando o caráter geral da teoria do emprego legada por Keynes, tornando-a um caso específico da própria teoria clássica criticada pelo autor ${ }^{17}$. A teoria da Demanda Efetiva foi deixada de lado, sendo substituída por uma teoria na qual se salienta a importância dos gastos agregados (autônomos), mas sem relação com a incerteza nem com a natureza convencional das expectativas e das decisões dos agentes. A própria economia volta a ser concebida como tendendo ao equilíbrio de pleno emprego no longo prazo. Em decorrência, as contribuições desses autores ligados à "síntese", se fossem classificadas de acordo com a perspectiva convencional, seriam neoclássicas. Robinson (1970) nega inclusive a legitimidade dessas abordagens em relação à Revolução Keynesiana, denominando seus praticantes de keynesianos bastardos.

Se a teoria keynesiana perdeu seus elementos mais revolucionários, a teoria neoclássica também não se acomodou bem com as contribuições da nova corrente. A tentativa de se pensar a economia em termos agregados fez com que os microfundamentos nos quais se assentava o neoclassicismo ficassem comprometidos. Na Macroeconomia moderna, segundo Blaug (1990) os resultados agregados das escolhas individuais são determinados segundo uma regra global definida, sem que se consiga, necessariamente, demonstrar por que razão tal regra global funciona. A rigidez de preços e salários, por exemplo, usada para justificar o desemprego, é incompatível com as noções de otimização e market-clearing neoclássicos. Outra incompatibilidade é com a função consumo, não derivando seus resultados de comportamentos de maximiza-

16 Essa contribuição saiu do estudo de William Phillips de 1958, mostrando uma correlação negativa entre inflação e desemprego para o Reino Unido (para dados do período de 1861 a 1957). As conclusões desse estudo foram confirmadas para os Estados Unidos por Samuelson e Solow, em seguida recebendo a generalização num modelo, segundo o qual se postula que uma menor taxa de desemprego leva a um aumento da inflação, e uma maior taxa de desemprego a uma menor inflação. As evidências da Curva de Phillips, contudo, deixaram de ser verificadas de forma empírica na década de 1970, pois as maiores economias do mundo experimentaram altas taxas de inflação e de desemprego simultaneamente.

17 Armadilha da liquidez, rigidez no mercado de trabalho e insensibilidade dos investimentos à taxa de juros são as situações nas quais as políticas keynesianas far-se-iam necessárias. 
ção individuais. Portanto, se forem aplicados os critérios de classificação de Keynes (macro), as contribuições dessa corrente deveriam ser enquadradas, ainda que com ressalvas, junto à dos defensores dos princípios da Demanda (Agregada).

\subsection{UMA CONTRARREVOLUÇÃO MONETARISTA?}

Nas décadas seguintes à "segunda síntese" surge o movimento denominado monetarismo. Este ocorre a partir das contribuições de Milton Friedman e se dá em três fases. Na primeira há a reexposição da velha Teoria Quantitativa da Moeda, com a demanda da moeda sendo determinada não mais pelo nível de produto, mas pela demanda por parte das empresas e famílias. Na segunda, Friedman apresenta seus argumentos fazendo uso do modelo IS/LM, legado pela "segunda síntese", por entender que isso permitiria captar o específico da posição a qual defendia em relação à dos keynesianos. Essa posição teria a haver com “... os diferentes pressupostos dinâmicos sobre o caminho de ajustamento e discrepâncias entre a quantidade de dinheiro que o público quer manter e a quantidade que de fato retém" (BLAUG, 2006, p. 195). Portanto, ao mesmo tempo em que Friedman concordava com os keynesianos sobre a capacidade das políticas intervencionistas em alterar o nível de produto no curto prazo, foi muito reticente também quanto a afirmar sobre a possibilidade de se praticar políticas monetárias discricionárias de estimulo à Demanda Agregada. A alegação é a de se saber pouco de política monetária para se praticar políticas de "sintonia fina". Seria preferível, nesse caso, políticas anunciadas de aumento no estoque de moeda consoante ao aumento do produto e ao aumento da velocidade de circulação da moeda ${ }^{18}$.

A terceira fase das contribuições de Milton Friedman dá-se no final dos anos 1960 e marca o início do declínio da "segunda síntese neoclássica" com a crítica à curva de Phillips com expectativas estáticas. Nesse momento, Friedman (1968) apresenta a noção de taxa natural, segundo a qual existe um nível de produto e uma taxa de desemprego a ele associada, determinada pela oferta de fatores de produção, tecnologia e instituições da economia. Mudanças na oferta de moeda e, consequentemente, na Demanda Agregada alteram o nível de renda no curto prazo. No longo prazo, entretanto, forças de equilíbrio fazem com que o desemprego volte ao nível da sua taxa natural. Com o tempo os agentes passariam a ajustar suas expectativas de modo que as políticas deixam de ter impacto, mesmo no curto prazo, trazendo como implicação somente uma taxa de inflação maior.

${ }_{18}$ Buscavam, dentre outras coisas, mostrar a inoperância da política fiscal, por pressuporem a rigidez da taxa de juros em relação à política monetária. 
Do ponto de vista da classificação convencional os monetaristas seriam, sem lugar à dúvida, neoclássicos, pois compartilham dos pressupostos microeconômicos desta escola. Na perspectiva macro, os monetaristas reconhecem que o nível de produto pode ser alterado por políticas de Demanda Agregada ${ }^{19}$, mas isso ocorre apenas ${ }^{20}$ e na medida em que há defasagem entre o valor das variáveis econômicas percebidas pelos agentes e seus valores reais. A tendência natural é a de o produto ser determinado por fatores reais no curto e no longo prazo. Por isso, dentro da perspectiva de Keynes, a Escola Monetarista seria mais bem classificada como clássica. O mais usual na história da análise econômica, entretanto, é ver as contribuições dessa escola classificadas de acordo com a perspectiva micro somente, ou seja, como parte da tradição neoclássica.

\subsection{A ECONOMIA NOVO-CLÁSSICA: EQUILÍBRIO DE MERCADO E EXPECTATIVAS RACIONAIS}

Os novo-clássicos surgiram em meio à crise econômica da década de 1970, a partir dos trabalhos de Robert Lucas como uma reação contra a ainda dominante corrente keynesiana ${ }^{21}$. Outros expoentes dessa Escola são Thomas J. Sargent, Robert Barro e Edward Prescott. O ponto de partida foram algumas sugestões monetaristas, apropriadas no sentido de promover uma ruptura mais fundamental com relação às ideias da "segunda síntese neoclássica". Por trás das suas construções está a ideia de dotar a Macroeconomia de microfundamentos. Os resultados agregados passariam a ocorrer em função da tomada de decisão individual, quando da alocação de recursos pelas empresas e unidades familiares. Alguns preceitos microeconômicos foram relaxados, como o de agentes racionais e informação perfeita. Em substituição concebe-se a ideia de que os agentes tomam decisões racionais sim, mas tendo em vista a disponibilidade de informações relevantes.

19 Em termos resumidos, os monetaristas, assim como os keynesianos, não concordam com a posição dos clássicos de que o produto no nível agregado seja completamente determinado pela oferta. A diferença é que os primeiros põem muito mais ênfase na oferta de moeda como determinante das flutuações econômicas.

${ }^{20}$ Friedman chega, como mencionado acima, a fazer uso do instrumental keynesiano, mas isso ocorre apenas enquanto pretende desconstruir seus resultados.

${ }^{21}$ A concepção de expectativas racionais, fundamental para os novo-clássicos, é atribuída ao trabalho de Mutt (1961), para quem as expectativas dos indivíduos são racionais quando são idênticas às predições desse modelo. Porém, no início da década de 1950, Kenneth Arrow já havia discutido em termos de formulação matemática as consequências das noções de expectativas racionais em um modelo de equilíbrio geral, num artigo de 1953 publicado na revista Econométrie n. 40, denominado Le rôle des valeurs boursières dans lallocation optimale des risqué. 
Para os economistas novo-clássicos, em termos agregados, vale a posição dos clássicos (segundo entendimento derivado de Keynes), ou seja, alterações no nível de renda de longo prazo ocorrem somente com alterações nos fatores reais, como tamanho da força de trabalho e estoque de capital. No curto prazo, os adeptos dessa escola aceitam os resultados empíricos que mostram alterações de produto decorrentes das políticas de Demanda Agregada expansionistas. Contudo, somente nos casos de políticas praticadas de maneira discricionária e de forma não prevista e não antecipada pelos agentes econômicos. Isto é o mesmo que admitir a existência de uma Curva de Phillips temporária. O uso sistemático e previsível de políticas discricionárias não teria efeitos reais, dado que os agentes incorporam às suas expectativas o comportamento errático das autoridades econômicas. $\mathrm{O}$ custo de se praticar tais políticas passaria a ser cada vez maior, em decorrência da perda de credibilidade e do fato dos agentes passarem a antecipá-las. Portanto, de uma maneira mais radical, estabelecem a não existência de dilema algum entre inflação e desemprego.

Não existe uma Macroeconomia neoclássica, pelo menos na extensão em que se aplicam o critério convencional (plano micro) e o de Keynes (plano macro). Isto é uma lacuna, já que aquilo que as contribuições de Lucas e seguidores têm são exatamente coerência e compatibilidade com outras definições de neoclassicismo em economia. Arida (2003, p. 23), por exemplo, define essa corrente, tanto no plano micro quanto no macro, como aquela que busca entender os “... fenômenos econômicos considerando que estes derivam de decisões individuais de agentes racionais". E isso é exatamente o que fazem os novo-clássicos, praticam uma Microeconomia e uma Macroeconomia cujos resultados dependem fundamentalmente da tomada ótima de decisões por firmas e unidades familiares, ao mesmo tempo em que defendem a noção de mercados autorregulados. $\mathrm{Na}$ ausência, entretanto, de um critério unificador como o acima citado, os novos clássicos devem continuar sendo definidos como neoclássicos na perspectiva convencional e clássicos na de Keynes.

\subsection{A ECONOMIA NOVO-KEYNESIANA}

A economia novo-keynesiana surge na década de 1980 e tem como principais representantes George Akerlof, Gregory Mankiw, Olivier Blanchard, Lawrence Summers, Paul Krugman e Joseph Stiglitz. A preocupação desses autores é produzir uma resposta às criticas dos economistas novo- clássicos de que a Macroeconomia precisava ser reconstruída sobre bases microeconômicas. Já nas décadas seguintes, passaram a representar o que seria o Novo Consenso Macroeconômico. 
A principal contribuição dos novo-keynesianos foi adicionar alguns elementos na explicação do desemprego involuntário dentro da tradição keynesiana. Nessa, o desemprego era explicado em função dos contratos de trabalho formulados em um ambiente de expectativas retrospectivas. Assim, em situações de queda na demanda agregada, os salários monetários permaneceriam fixos por tempo suficiente de modo a não permitir o retorno ao nível inicial de emprego. A crítica dos novo-keynesianos vai recair, segundo Snowdon e Vane (2005), na forma como a rigidez de preços e salários é abordada pelos velhos keynesianos, dentro de um esquema walrasiano, impedindo-os de considerar a relação com as rigidezes nominais ${ }^{22}$.

Apesar da diversidade de enfoques, alguns elementos comuns da pesquisa novo-keynesiana podem ser enumerados. Primeiro, pressupõem concorrência imperfeita para o mercado de produto. Segundo, além da rigidez do salário nominal, focam na rigidez de preços $^{23}$. E, por último, abordam tanto os fatores que causam a rigidez nominal quanto os que causam a rigidez das variáveis reais ou preços relativos das empresas. Com isso, os autores afiliados a essa corrente buscam explicar como as interações entre a rigidez nominal e as imperfeições reais afetam o comportamento dos preços e explicam o desemprego involuntário.

Os "Custos de Menu" constituem-se na principal rigidez estudada pelos novo-keynesianos. Esses implicam que firmas operando em mercados oligopolistas relutam alterar preços quando há variação na demanda agregada, evitando desencadearem rodadas competitivas. Outra forma de rigidez são os "salários eficiência". Como a eficiência dos trabalhadores aumenta com o salário real, há a percepção por parte das firmas de que mantendo um salário acima do valor de mercado haverá incentivos para o trabalhador não ser leniente. Com esse salário mais elevado evitam-se também os custos de recrutamento e treinamento do trabalhador, além de reforçar o moral e o compromisso com o trabalho.

Apesar de diferenças específicas, a corrente Novo-Keynesiana assim como as dos Velhos Keynesianos, Monetaristas e Novo-Clássicos, é defensora dos princípios de comportamento racional e ótimo econômico neoclássico. Do ponto de vista Macroeconômico, em virtude de atribuírem imperfeições aos mecanismos de mercado no curto prazo, concebem espaço para a prática de políticas de fomento à demanda por parte das autoridades econômicas. No longo prazo, o apelo dos seus praticantes é

\footnotetext{
${ }^{22}$ Algumas proposições podem ser reunidas para caracterizar o trabalho dos novo-keynesianos como: concorrência imperfeita, rigidez de preços e salários e rigidez real (fatores que provocam rigidez de preços relativos).

${ }^{23}$ Uma rigidez nominal ocorre se algo impede ajustes imediatos nos preços em decorrência de choques nominais. Uma rigidez real ocorre se algum fator impede os salários reais de se ajustarem ou se existe fricção de um salário relativo para outro, ou de um preço relativo para outro.
} 
similar ao dos adeptos da "segunda síntese", defendem o ajuste automático dos mercados e a existência de uma Curva de Phillips vertical. Ainda assim, não devem ser classificados como clássicos, estando mais para defensores do princípio da Demanda (Agregada), no sentido de que assumem a necessidade de intervenção do governo para ajustar desequilíbrios momentâneos e corrigir falhas de mercado. Segundo atesta o próprio Mankiw (2010) em um manual de economia de grande circulação, os mercados geralmente funcionam bem, embora algumas vezes os governos possam melhorar os resultados econômicos.

\subsection{A ECONOMIA PÓS-KEYNESIANA}

Em oposição à Macroeconomia do mainstream, existem os chamados pós-keynesianos. Essa corrente, conforme Lavoie (2014) engloba as vertentes fundamentalistas, robinsonianas (sraffianos ou neo-ricardianos), institucionalistas, kaleckianas e kaldorianas $^{24}$. Os manuais de história do pensamento, contudo, além de omitirem boa parte delas, considerando apenas os pós-keynesianos neo-ricardianos e os fundamentalistas, tratam-nas de forma indistinta. O que há de comum entre essas duas vertentes, segundo Amadeo e Dutt (1987), é o fato de afirmarem a insuficiência da flexibilidade dos salários monetários como elemento capaz de conduzir a economia para o pleno emprego. Para Lovoie (2014), o traço característico que as une é que ambas afirmam ser a economia dirigida pela demanda, tanto no curto quanto no longo prazo.

Pode-se dizer, com relação às diferenças específicas entre os pós-keynesianos neo-ricardianos e os fundamentalistas, que os primeiros se apoiam principalmente nos pressupostos ricardianos e neo-ricardianos sobre a determinação do valor do produto. Autores como Pierangelo Garegnani, John Eatwell e Murray Milgate buscam inspiração em Sraffa (1960), cuja obra Produção de Mercadorias por Meio de Mercadorias, oferece uma versão mais sofisticada da teoria do valor de Ricardo, em contraposição à teoria da utilidade marginal. A ideia de mercadoria padrão de Sraffa ao mesmo tempo em que resolve o problema da medida invariável de valor, oferece a chave "para estabelecer o elo entre a análise de Marx da natureza e a origem do lucro e sua análise dos preços de produção" (HUNT e LAUTZEHEISER, 2011, p. 515). Os pós-keynesianos neoricardianos, conforme Screpanti e Zamagini (2005), buscam fundamento microeconômico também nos trabalhos inovadores de Bain, Sylos-Labini e Eichner sobre a teoria da firma, os quais permitem dotar a Macroeconomia de

${ }^{24}$ Um passo necessário seria no sentido de uma abordagem que integrasse essas correntes dando-lhes coerência interna. 
microfundamentos radicalmente distintos dos neoclássicos. Essas análises descrevem o comportamento dos custos médios e marginais de tal modo que corrobora a existência de mecanismos de fixação de preços extra concorrenciais, como o Mark-up. A consequência é um ambiente no qual as decisões macroeconômicas por parte dos empresários envolvem conflito distributivo e a percepção da existência de flutuações econômicas imprevisíveis ${ }^{25}$.

Já os pós-keynesianos fundamentalistas, com destaque para Paul Davidson, Hyman Minsky e Jan Kregel, surgem no início dos anos 1970 como contraposição não somente aos monetaristas e novos clássicos, mas à própria síntese de Hicks e Samuelson. Seus trabalhos se baseiam numa interpretação, autointitulada, de canônica da obra de Keynes. São também chamados de "não reconstruídos" por procurarem resgatar algumas ideias centrais do autor, como desemprego involuntário e a noção original de Demanda Efetiva. Essa corrente de pensamento pressupõe duas propriedades fundamentais sobre o mundo real, a não neutralidade da moeda e a incerteza sobre o futuro. Tudo isso num contexto histórico concreto no qual as decisões são irreversíveis, daí a noção de tempo histórico em oposição ao tempo lógico neoclássico. Partindo desses conceitos, concluem pela impossibilidade de uma economia deixada às forças de mercado atingir e permanecer em uma posição de pleno emprego da força de trabalho, defendendo em contraposição, a permanente participação do governo na economia.

Apesar de tentativas de conciliar as duas correntes, principalmente pela complementaridade das suas pesquisas, pós-keynesianos neo-ricardianos e fundamentalistas continuam, portanto, mantendo unidade apenas na crítica ao mainstream (CARDIM, 1990). Pode-se dizer em adição que, pela perspectiva micro, os neo-ricardianos se aproximam dos clássicos por aderirem à teoria do valor trabalho de Sraffa, além de usarem o seu instrumental para enfatizar todas as imperfeições alocativas dos mercados; do ponto de vista macro apontam para a existência de desemprego involuntário, em função dos desajustes entre poupança e investimentos. Enquanto isso, os fundamentalistas teriam uma abordagem micro mais próxima à de Marshall, afirmando as noções de rendimentos decrescentes e de concorrência pura (LAVOIE, 2014); no plano macro, seriam adeptos do princípio da Demanda Efetiva, influenciados pela análise dos escritos de Keynes anteriores à Teoria Geral.

25 Os pós-keynesianos fundamentalistas não estão de acordo com essa microfundamentação. Até mesmo porque os trabalhos citados partem da consideração de que existem estruturas de mercado. Numa verdadeira microeconômica clássica, as empresas operariam em regime de concorrência pura (não perfeita). 


\section{CONCLUSÃO}

A Macroeconomia moderna, como se pode observar, é um território propenso a problemas de classificação, com os historiadores das ideias tentando enquadrar ao mesmo tempo autores e correntes segundo pontos de vistas distintos. Ainda que não seja possível estabelecer um corte transversal unindo distintas perspectivas, pode-se traçar pontos de aproximação e ao mesmo tempo problematizar a forma como são apresentadas as contribuições ao pensamento macroeconômico.

Foi constatado, por exemplo, que duas perspectivas nem sempre explicitadas são colididas para classificar as escolas macroeconômicas, a saber, a macro de Keynes e a convencional. Do ponto de vista macro, os defensores do uso de políticas econômicas governamentais proativas, denominados keynesianos, são contrapostos aos clássicos, defensores do automatismo do mercado e da economia laissez-faire. Do ponto de vista micro, boa parte daqueles considerados clássicos e keynesianos na definição macro, passa a receber a denominação de neoclássicos, por pretenderem estender os princípios de tomada de decisão individual à Macroeconomia.

De modo mais específico, pode-se estabelecer que no plano macro os keynesianos da "segunda síntese neoclássica" não pertencem à escola clássica (definida por Keynes), mas são adeptos do princípio da Demanda Efetiva, ainda que parcialmente e apenas enquanto advoguem a necessidade das políticas de administração da Demanda Agregada, ou gastos autônomos; no plano micro, junto com os novo-keynesianos, monetaristas e novo-clássicos, são defensores dos postulados de racionalidade, equilíbrio e ótimo econômico, por isso são neoclássicos. Os novo-clássicos constituem um caso interessante, pois sustentam tanto o entendimento de market-clearing instantâneo quanto o fato de o nível de renda agregada ser determinado pelas decisões de agentes racionais.

No lado oposto ao das correntes dominantes, há a macroeconomia dos pós-keynesianos. Esta promove uma ruptura de fato com a tradição clássica (definida por Keynes) e neoclássica (definição convencional). O cerne das proposições dos pós-keynesianos fundamentalistas é o princípio da Demanda Efetiva, ao mesmo tempo em que chamam a atenção para a incerteza, para a importância da moeda e para a consideração do tempo histórico na análise econômica. O dos pós-keynesianos neo-ricardianos é a adesão à teoria do valor dos clássicos (definição convencional), incorporando as contribuições de Sraffa. Essas duas correntes heterodoxas, contudo, ressentem de uma síntese unindo suas perspectivas.

Constatou-se que algumas das indefinições na compreensão da Macroeconomia persistem pelo fato de se tentar enquadrar ao mesmo tempo autores e escolas segundo pontos de vistas diferentes. A indefinição mais frequente surge da classificação das 
contribuições à Macroeconomia segundo a perspectiva micro, sumarizada por Joan Robinson, e a macro de Keynes. Ao ter procurado sistematizar as distinções existentes entre essas perspectivas, espera-se, portanto, que o presente trabalho tenha contribuído para tornar mais claros os aspectos coincidentes e contraditórios das teorias macroeconômicas.

\section{REFERÊNCIAS BIBLIOGRÁFICAS}

AMADEO, E.; DUTT, A. Os keynesianos neo-ricardianos e os pós-keynesianos. Pesquisa e Planejamento Econômico, v. 17, n. 3, dez. 1987.

ARIDA, P. "A história do pensamento econômico como teoria e retórica”. In: REGO, J.; GALA, P. (Orgs.). A história do pensamento econômico como teoria e retórica. São Paulo: Editora 34, 2003.

BEAUD, M.; DOSTALER, G. Economic Thought since Keynes: a history and dictionary of major economists. New York: Routledge, 1995.

CARDIM, C. Resenha Bibliográfica. Keynes's Third Alternative? The neo-ricardian keynesians and the post keynesians. Pesquisa e Planejamento Econômico, v. 20, n. 3, p. 641-646, dez. 1990.

COLANDER, D. The death of neoclassical economics. Journal of the History Thought, v. 22, n. 2,2000 .

COLANDER, D.; HOLT, R.; ROSSER Jr, J. B. The changing face of mainstream economics. Review of Political Economy, v. 16, n. 4, 2004.

BACKHOUSE, R. History of Modern Economic Analysis. Oxford: Basil Blackwell, 1985.

BACKHOUSE, R. Interpreting Macroeconomics: explorations in the history of economic thought. New York: Routledge, 1996.

BLAUG, M. Economic theory in retrospect. 4. ed. Cambridge, MA: Cambridge University Press, 1990.

BLAUG, M. The methodology of economics: or how economists explain. 2. ed. Cambridge, MA: Cambridge University Press, Cengage Learning, 2006.

BRUE, S.; GRANT, R. R. The evolution of economic though. 8. ed. Cambridge, MA: Cengage Learning, 2012.

DE VROEY, M.; DUARTE, P. G. In search of lost time: the neoclassical synthesis. The B. E. Journal of Macroeconomics, v. 13, p. 1-31, 2013.

DEANE, P. A evolução das ideias econômicas. Rio de Janeiro: Zahar, 1980.

EKELUND, R.; HÉBERT, F. A history of economic theory and method. 5. ed. Long Grove, Ill.: Waveland, 2007.

FONSECA. P. Clássicos, neoclássicos e neokeynesianos: uma tentativa de sistematização. Perspectiva Econômica, v. 11, n. 30, p. 35-64, 1981. 
FRIEDMAN. M. The role of monetary policy. American Economic Review, v. 58, n. 1, p. 1-17, mar. 1968.

HANSEN, A. Mr. Keynes on underemployment equilibrium. Journal of Political Economy, v. 44, p. 667-686, 1936.

HICKS, J. Mr. Keynes and the "Classics": a suggested interpretation. Econometrica, v. 5, n. 2, p. 147-159, 1937.

HOBSBAWN, H. "Inventing traditions". In: HOBSBAWN, H.; RANGER, T. (Orgs.). The invention of tradition. Cambridge: Cambridge University Press, 2012.

HUNT, E.; LAUTZEHEISER, M. History of economic thought: a critical perspective. 3. ed. London and New York: Routledge Taylor e Francis Group, 2011.

JEVONS, S. A teoria da economia política. (Os Economistas). São Paulo: Abril Cultural, 1983.

KEYNES, J. A Teoria geral do emprego, do juro e da moeda. (Os Economistas). São Paulo: Abril Cultural, 1983.

KLAMER, A. Conversations with economists: new classical economists and opponents speak out on the current controversy in macroeconomics. Totowa: Rowman and Allanheld, 1983.

LANDRETH, H.; COLANDER, D. History of economic thought. 4. ed. Boston/Toronto: Houghton Mifflin Company, 2001.

LAKATOS, I. "Falsification and the methodology of scientific research programs". In: LAKATOS, I.; MUSGRAVE, A. (Orgs.). Criticism and the growth of knowledge. Cambridge: Cambridge University Press, 1970, p. 91-195.

LAVOIE, M. Post Keynesian economics: new foundations. Northampton: Edward Elgar Publishing, 2014.

LEIJONHUFVUD, A. On Keynesian Economics and the Economics of Keynes: a study in monetary theory, New York: Oxford University Press, 1968.

MANKIW, G. Macroeconomia. 7. ed. Rio de Janeiro: LTC, 2010.

MARSHALL, A. Principles of economics. 8. ed. Londres: Macmillan, 1920.

MEEK, R. Economia e ideologia. O desenvolvimento do pensamento econômico. Rio de Janeiro: Zahar Editores, 1971.

MENGER, K. Princípios de econômica política. (Os Economistas). São Paulo: Abril Cultural, 1983.

MILONAKIS, D.; FINE, B. From political economy to economics: Method, the social and the historical in the evolution of economic theory (Economics as Social Theory). New York: Routledge, 2009.

MUTH, J. Rational expectations and the theory of price movements. Econometrica, v. 29, n. 3, jul. 1961.

PHELPS, E. Seven schools of macroeconomic thought. Clarendon Press: Oxford, 1990.

RIMA, I. Development of economic analysis. 7. ed. Abingdon: Routledge, 2008.

ROBBINS, L. A history of economic thought. Princeton: Princeton University Press, 1998. 
ROBINSON, J. Economic heresies: some old-fashioned questions in economic theory. London: Macmillan, 1970.

ROBINSON, J.; EATWELL, J. Introdução à economia. Rio de Janeiro e São Paulo: Livros Técnicos e Científicos Editora, 1978.

SAMUELS, W.; HENDERSON, W; D. JOHNSON, K; e JOHNSON, M. Essays on the history of economics. London: Routledge, 2004.

SAMUELSON, P. Economics. 3. ed. New York: McGraw-Hill, 1955.

SCHUMPETER, J. A. Teorias econômicas: de Marx a Keynes. Rio de Janeiro: Zahar, 1970.

SCREPANTI, E.; ZAMAGNI, S. An outline of the history of economic thought. 2. ed. Oxford: Oxford University Press, 2005.

SNOWDON, B.; VANE, H. A modern macroeconomics. Its origins, development and current state. Cheltenham: Edward Elgar, 2005.

TOGATI, D. T. Keynes and the neoclassical synthesis. Einsteinian versus Newtonian macroeconomic studies in the history. New York: Routledge, 1998.

WALRAS, L. Elements of Pure Economics. London: Routledge Library Editions, 2010 [1874]. 